\title{
Decreased CSF Dynamics in Treatment-Naive Patients with Essential Hypertension: A Study with Phase-Contrast Cine MR Imaging
}

\author{
(D) $\mathrm{La}$, (D)W. He, (D) X. Li, (D)X. Liu, (D) H. Cao, (D) L. Guo, (D) X. Xiao, (D) Y. Xu, and (D) Y. Wu
}

\begin{abstract}
BACKGROUND AND PURPOSE: Arterial sclerosis resulting from hypertension slows CSF transportation in the perivascular spaces, showing the intrinsic relationship between the CSF and the blood vasculature. However, the exact effect of hypertension on human CSF flow dynamics remains unclear. The present study aimed to evaluate CSF flow dynamics in treatment-naive patients with essential hypertension using phase-contrast cine MR imaging.
\end{abstract}

MATERIALS AND METHODS: The study included 60 never-treated patients with essential hypertension and 60 subjects without symptomatic atherosclerosis. CSF flow parameters, such as forward flow volume, forward peak velocity, reverse flow volume, reverse peak velocity, average flow, and net flow volume, were measured with phase-contrast cine MR imaging. Differences between the 2 groups were assessed to determine the independent determinants of these CSF flow parameters.

RESULTS: Forward flow volume, forward peak velocity, reverse flow volume, reverse peak velocity, and average flow in the patients with hypertension significantly decreased (all, $P<.05$ ). Increasing systolic blood pressure was significantly associated with lower forward flow volume $(\beta=-0.44 \mathrm{~mL} / \mathrm{mL} / \mathrm{mm} \mathrm{Hg} ; 95 \% \mathrm{Cl},-0.83$ to $-0.06 \mathrm{~mL} / \mathrm{mL} / \mathrm{mm} \mathrm{Hg})$, forward peak velocity $(\beta=-0.50 \mathrm{~cm} / \mathrm{s} / \mathrm{mm} \mathrm{Hg} ; 95 \% \mathrm{Cl}$, -0.88 to $-0.12 \mathrm{~cm} / \mathrm{s} / \mathrm{mm} \mathrm{Hg})$, reverse flow volume $(\beta=-0.61 \mathrm{~mL} / \mathrm{mL} / \mathrm{mm} \mathrm{Hg} ; 95 \% \mathrm{Cl},-0.97$ to $-0.26 \mathrm{~mL} / \mathrm{mL} / \mathrm{mm} \mathrm{Hg})$, reverse peak velocity $(\beta=-0.55 \mathrm{~cm} / \mathrm{s} / \mathrm{mm} \mathrm{Hg} ; 95 \% \mathrm{Cl},-0.91-0.18 \mathrm{~cm} / \mathrm{s} / \mathrm{mm} \mathrm{Hg})$, and average flow $(\beta=-0.50 \mathrm{~mL} / \mathrm{min} / \mathrm{mm} \mathrm{Hg} ; 95 \% \mathrm{Cl},-0.93 \mathrm{to}$ $-0.08 \mathrm{~mL} / \mathrm{min} / \mathrm{mm} \mathrm{Hg}$ ).

CONCLUSIONS: The CSF flow dynamics in patients with hypertension are decreased, and increasing systolic blood pressure is strongly associated with lower CSF flow dynamics.

ABBREVIATIONS: AF = average flow; DBP = diastolic blood pressure; FFV = forward flow volume; FPV = forward peak velocity; RFV = reverse flow volume; NFV = net flow volume; PCC-MRI = phase-contrast cine MR imaging; PP = pulse pressure; RPV = reverse peak velocity; SBP = systolic blood pressure

$\mathbf{T}$ he brain consists of 4 fluid compartments: CSF, interstitial fluid, intracellular fluid, and blood. In mammals, CSF comprises $10 \%$ of the total fluid volume within the cranial cavity. ${ }^{1} \mathrm{CSF}$ formed in the choroid plexi flows through the cerebral ventricles

Received January 8, 2021; accepted after revision August 5

From the Department of Medical Imaging (L.M., X. Li, X. Liu, H.C., L.G., X.X., Y.X., Y.W.), Nanfang Hospital, Southern Medical University, Guangzhou, China; and Department of Radiology (W.H.), Guangdong 999 Brain Hospital, Guangzhou, China.

Lichao Ma and Wenle He contributed equally to data postprocessing and writing of this study and were considered co-first authors.

This study has received funding from the Natural Science Foundation of Guangdong Province, China (grant No. S201301005689), the Science and Technology Program of Guangzhou, China (grant No. 201707010003), and the Special Foundation of President of Nanfang Hospital, Southern Medical University (grant No. 2016B026).

Please address correspondence to Yuankui Wu, MD, Department of Medical Imaging, Nanfang Hospital, Southern Medical University, Guangzhou, China; e-mail: ripleyor@126.com

- Indicates open access to non-subscribers at www.ajnr.org

http://dx.doi.org/10.3174/ajnr.A7284 and the subarachnoid space to its ultimate sites of reabsorption into the bloodstream via arachnoid villi of the dural sinuses, along cranial nerve sheaths and the spinal nerve root or through the nasal lymphatics. ${ }^{2,3}$ This conventional view, however, has been challenged by the new findings in a recent study: Subarachnoid CSF rapidly enters the brain parenchyma along with arterial perivascular spaces, and this flow plays a vital role in driving the clearance of metabolic waste from the interstitial fluid at more downstream locations. ${ }^{1,2}$ Furthermore, a study in mice demonstrated that arterial sclerosis resulting from hypertension disrupts this pump of CSF transportation in the perivascular spaces and sharply slows interstitial fluid waste removal. ${ }^{4}$ These studies have shown that an intrinsic relationship lies between the 2 brain fluid compartments, CSF and blood vasculature. At present, however, the exact effect of hypertension on human CSF dynamics is unclear. Accurate assessment of CSF dynamics characteristics in patients with hypertension may have both potential clinical value and scientific significance. 


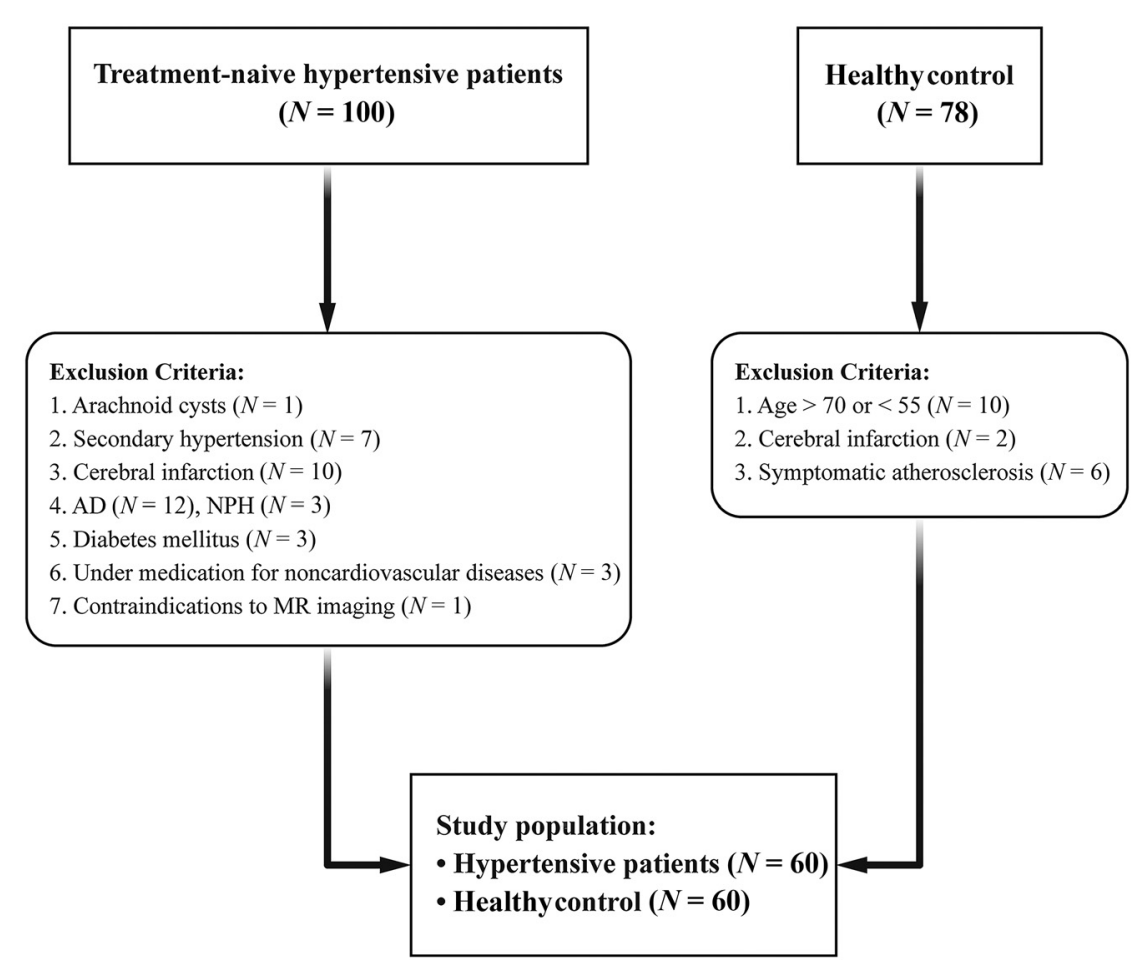

FIG 1. Flow chart of the study population.

The relative inaccessibility of the subarachnoid space impedes the pace of investigations in this area. To date, invasive techniques, such as spinal puncture with the introduction of contrast medium, have been the mainstay of the investigation of CSF flow dynamics. ${ }^{5}$ Phase-contrast cine MR imaging (PCC-MRI) is extremely sensitive even to very slow flow. Studies have shown that PCC-MRI can give quantitative and qualitative information noninvasively and within a short analysis time on CSF flow physiology without the need for injection of contrast agent and x-ray exposure. ${ }^{6-9}$ PCCMRI has played an important role in the diagnosis of communication hydrocephalus, obstructive hydrocephalus, spontaneous intracranial hypotension/hypertension, and many other diseases. ${ }^{6,10-14}$

To the best of our knowledge, however, there are no studies in the literature concerning the impact on CSF flow dynamics on established hypertension. Therefore, we hypothesized that PCCMRI can assess the effect of hypertension on human CSF dynamics. In this study, PCC-MRI was used to evaluate the CSF flow dynamics in patients with hypertension.

\section{MATERIALS AND METHODS \\ Study Participants}

This prospective study received ethics approval from the local Medical Ethics Committee and informed consent was obtained for all patients. We studied 100 patients with hypertension visiting the outpatient clinic of our hospital (Nanfang Hospital Southern Medical University), and eventually, 60 patients were enrolled (Fig 1) (31 men; 55-70 years of age; mean age, 61.24 years [SD, 8.93] years; disease duration [from the onset of hypertension to the date of brain MR imaging] 4.92 [SD, 2.72] years) with never-treated essential hypertension. Patients reported that their blood pressure was found elevated either by medical personnel during a routine annual checkup or by themselves accidentally. Patients with arachnoid cysts $(n=1)$, secondary hypertension $(n=7)$, cerebral infarction $(n=10)$, specific types of brain atrophy (Alzheimer disease, $n=12$, and normal-pressure hydrocephalus, $n=3$ ), diabetes mellitus $(n=3)$, as well as those patients under medication for noncardiovascular diseases $(n=3)$ were excluded from the study. Patients with contraindications to MR imaging (ie, pacemaker and claustrophobia) were also excluded $(n=1)$.

We studied 78 patients visiting the outpatient clinic of our hospital, and eventually, 60 control subjects were enrolled (Fig 1) (33 men; 55-70 years of age; mean age, 60.38 [SD, 7.54] years) without symptomatic atherosclerosis or abnormalities on MR imaging and MRA of the brain who were matched for age and sex with the patients. Patients older than 70 years of age or younger than 55 years of age $(n=10)$ and those with cerebral infarction $(n=2)$ and symptomatic atherosclerosis $(n=6)$ were excluded from the study.

All patients with hypertension and controls were subject to 3 office blood pressure measurements.

\section{Office Blood Pressure Measurement}

Morning office blood pressure was measured with the patient in the supine position by the wrist electronic blood pressure monitor (EW3005, Panasonic) in the operating room 30 minutes before the MR imaging examination, approximately at the same morning hour of the day, by the same cardiologist with a mercury sphygmomanometer (first and fifth phases of Korotkoff sounds taken as systolic blood pressure [SBP] and diastolic blood pressure [DBP], respectively) after the subjects had rested for 5-10 minutes in a sitting position. Three measurements were taken at 1 -minute intervals, and the average was used to define clinical SBP and DBP. Office pulse pressure (PP) was calculated as SBP-DBP. ${ }^{15}$ Hypertension was diagnosed with the patient having SBP $>140 \mathrm{~mm} \mathrm{Hg}$ or DBP $>90 \mathrm{~mm} \mathrm{Hg}$ according to the Seventh Report of the Joint National Committee on Prevention, Detection, Evaluation and Treatment of High Blood Pressure guidelines. ${ }^{16}$ Subjects were required to avoid smoking or drinking coffee at least for 2 hours before the examination.

\section{MR Imaging Acquisition}

MR imaging was performed with a clinical 3T imaging unit equipped with an 8-channel head coil (Achieva; Philips Healthcare). Each subject underwent both conventional MR 


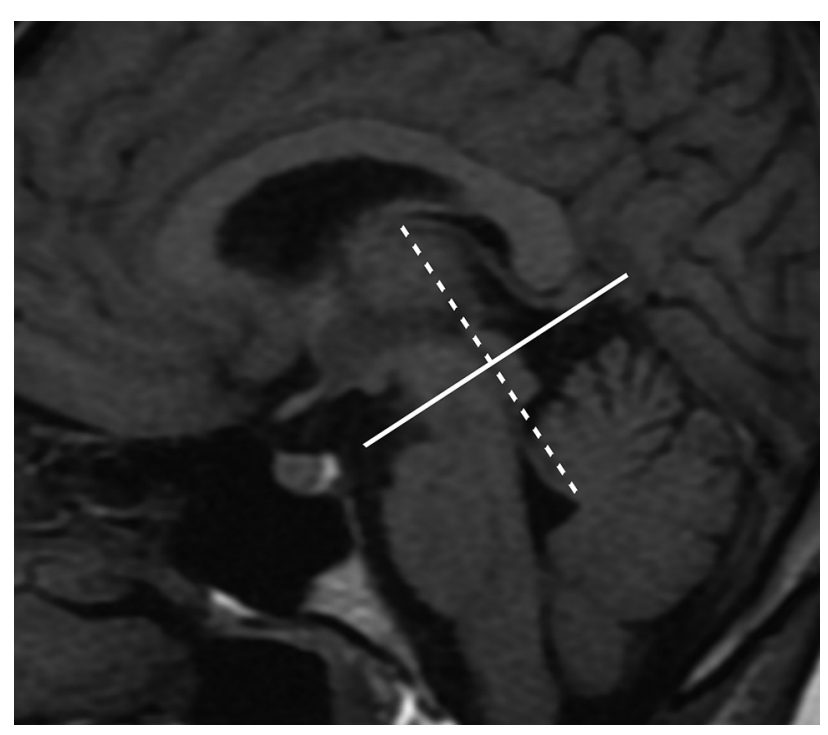

FIG 2. Illustration of the location of phase-contrast MR imaging planes. The midline sagittal TIWI MR image shows the phase-contrast MR imaging planes (solid line) located at the ampulla level of the cerebral aqueduct and perpendicular to its long axis (dotted line).

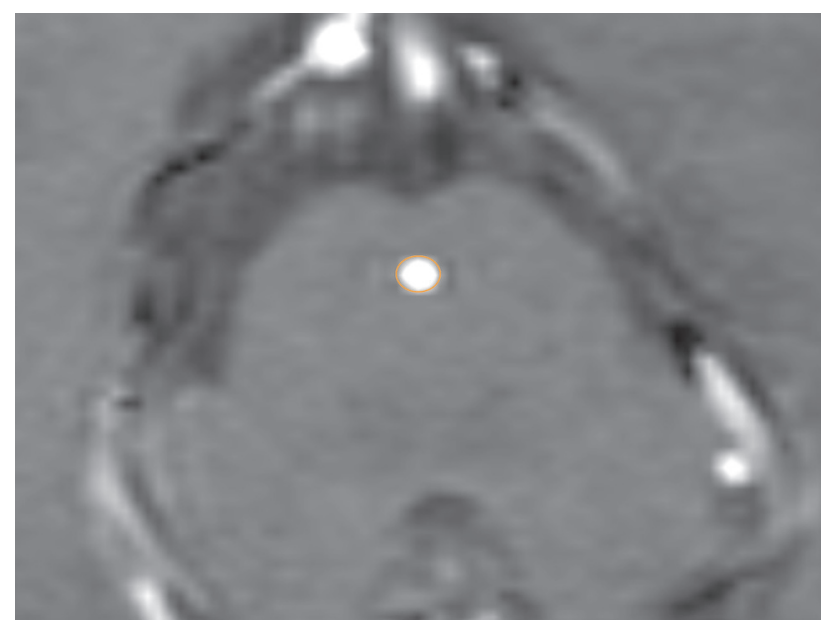

FIG 3. Placement of ROI to contain the whole aqueduct.

imaging and PCC-MRI; the controls underwent MRA in the same session.

Conventional MR images included axial FLAIR (TR/TI/TE $=$ $11,000 / 2200 / 125 \mathrm{~ms}$, voxel size $=0.7 \times 0.7 \times 6 \mathrm{~mm}^{3}, 20$ slices), axial T2WI $\left(\mathrm{TR} / \mathrm{TE}=3000 / 80 \mathrm{~ms}\right.$, voxel size $=0.5 \times 0.7 \times 6 \mathrm{~mm}^{3}, 20 \mathrm{sli}-$ ces), axial T1WI $(\mathrm{TR} / \mathrm{TE}=2000 / 20 \mathrm{~ms}$, voxel size $=0.5 \times 0.9 \times 6$ $\mathrm{mm}^{3}, 20$ slices), and sagittal T1WI (TR/TE $=2000 / 20 \mathrm{~ms}$, voxel size $=0.7 \times 0.9 \times 6 \mathrm{~mm}^{3}, 20$ slices). Each healthy subject also underwent MRA. Parameters for the MRA pulse sequence were $\mathrm{TR} / \mathrm{TE}=23 / 3.5 \mathrm{~ms}$, voxel size $=0.45 \times 0.68 \times 1.2 \mathrm{~mm}^{3}, 140$ slices.

Parameters for the PCC-MRI pulse sequence were the following: velocity encoding $=10 \mathrm{~cm} / \mathrm{s}, \mathrm{FOV}=150 \times 150 \mathrm{~mm}$, section thickness $=4 \mathrm{~mm}$, matrix $=256 \times 178, \mathrm{TR}=24 \mathrm{~ms}, \mathrm{TE}=14 \mathrm{~ms}$, flip angle $=15^{\circ}$, and 16 frames per cardiac cycle with peripheral retrospective pulse gating. The scans were obtained on sagittal T1-weighted imaging perpendicular to the CSF flow direction at the ampulla of the aqueduct (Fig 2). The "craniocaudal flow direction" was defined as positive, and the "caudocranial flow direction" was defined as negative. The scanning time for each patient was approximately 5 minutes.

\section{Imaging Analysis}

All the MR imaging analyses were performed in a blinded manner. Two neuroradiologists (L. M. and Y. W., with 7 and 20 years of experience, respectively) reviewed the MR images. No obvious abnormalities were found on conventional MR imaging and MRA in the controls and conventional MR imaging in patients with hypertension. Quantitative measurements of CSF flow at the ampulla of the aqueduct were processed using the Philips Q-flow software on the EWS MR imaging workstation. CSF flow quantification was performed on phase images showing maximum velocity, flow values, and velocity-time curves, which can change during the cardiac cycle using ROI measurements. The ROI measurement was performed by one of the authors on the independent console (Fig 3). Any type of dispute was resolved through consensus. The 16 axial sections, crossing the ampulla of the aqueduct and obtained in a cardiac cycle, were opened with Q-flow software. The ROI placement on the ampulla of the aqueduct was performed manually for each of 16 axial sections to obtain a quantitative measurement, separately. During the cardiac cycle, the software automatically calculated the forward flow volume (CSF flow volume toward the fourth ventricle) (FFV), reverse flow volume (CSF flow volume toward the third ventricle) (RFV), net flow volume flowing through the cerebral aqueduct in each cardiac cycle (NFV) (in milliliters), forward peak velocity (maximum velocity toward the fourth ventricle) (FPV), and the reverse peak velocity (maximum velocity toward the third ventricle, centimeters/second) (RPV) in each cardiac cycle. Additionally, the software automatically calculated the average flow (average of the absolute values of the bidirectional flow) (AF) through the cerebral aqueduct per minute (milliliter/minute).

\section{Statistical Analysis}

All descriptive and statistical analyses were performed using SPSS (Version 20.0; IBM). All the CSF flow parameters (FFV, FPV, RFV, $\mathrm{RPV}, \mathrm{AF}$, and NFV) between patients and control subjects were compared using the Student unpaired $t$ test. In the hypertension group, univariate linear regression was performed for determinants of these parameters. To ascertain independent determinants of these parameters, we performed multiple linear regression analysis after evaluating whether the continuous variables were normally distributed. For each factor, we calculated the adjusted regression coefficients $(\beta)$, which yielded the slope of the regression that was fitted by the model and indicated the increase (positive value) or decrease (negative value) in these parameters. For the test results, $95 \%$ confidence intervals are given. ${ }^{17} \mathrm{~A} 95 \% \mathrm{CI}$ that did not include the value of 0 had a $P$ value $<.05$.

\section{RESULTS}

Characteristics of the study population are summarized in Table 1. There were no significant differences in age $(P=.84)$ or sex $(P=.71)$ between the 2 groups.

CSF flow parameters between the patients with hypertension and the control group are given in Table 2. FFV, FPV, RFV, RPV 
Table 1: Clinical characteristics of patients with essential hypertension and healthy subjects

\begin{tabular}{lccr}
\hline \multicolumn{1}{c}{ Characteristics } & Patients & Controls & $P$ Value \\
\hline No. & 60 & 60 & \\
Age (mean) (yr) & $61.24(\mathrm{SD}, 8.9)$ & $60.38(\mathrm{SD}, 7.54)$ & .84 \\
Male & 31 & 33 & .71 \\
PP (mean) (mm Hg) & $53.78(\mathrm{SD}, 14.86)$ & $42.43(\mathrm{SD}, 4.36)$ & $<.001$ \\
SBP (mean) $(\mathrm{mm} \mathrm{Hg})$ & $148.54(\mathrm{SD}, 13.55)$ & $123.40(\mathrm{SD}, 6.06)$ & .001 \\
DBP (mean) $(\mathrm{mm} \mathrm{Hg})$ & $94.76(\mathrm{SD}, 7.72)$ & $80.97(\mathrm{SD}, 2.42)$ & $<.001$ \\
Disease duration (mean) $)$ & $4.92(\mathrm{yr})$ & 0 & $<.001$ \\
\hline
\end{tabular}

Table 2: Comparison of mean CSF flow parameters in the hypertension and control groups

\begin{tabular}{lcccccc}
\hline Group & FFV $(\mathrm{mL})$ & FPV $(\mathrm{cm} / \mathrm{s})$ & RFV $(\mathrm{mL})$ & RPV $(\mathrm{cm} / \mathrm{s})$ & AF $(\mathrm{mL} / \mathrm{min})$ & $\mathrm{NFV}(\mathrm{mL})$ \\
\hline Patients & $0.054(\mathrm{SD}, 0.021)$ & $5.338(\mathrm{SD}, 2.024)$ & $0.042(\mathrm{SD}, 0.019)$ & $4.837(\mathrm{SD}, 2.196)$ & $7.480(\mathrm{SD}, 3.221)$ & $0.012(\mathrm{SD}, 0.005)$ \\
Controls & $0.080(\mathrm{SD}, 0.040)$ & $6.197(\mathrm{SD}, 2.394)$ & $0.070(\mathrm{SD}, 0.042)$ & $5.823(\mathrm{SD}, 2.821)$ & $9.824(\mathrm{SD}, 5.435)$ & $0.010($ (SD, 0.011) \\
$P$ value & $<.001$ & .04 & .005 & .04 & .006 & .12 \\
\hline
\end{tabular}

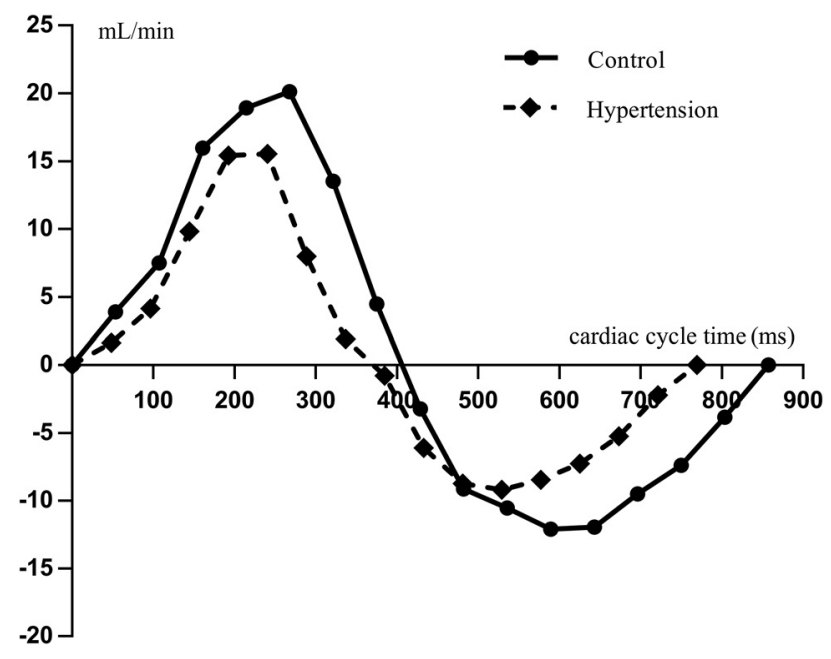

FIG 4. Flow curves of the essential hypertension and control groups. Flows are plotted during the successive phases of a cardiac cycle time (millisecond) and expressed in milliliter/minute. Each flow curve for both groups represents average flow values. Positive deflections represent craniocaudal flow (CSF systole), and negative deflections represent caudocranial flow (CSF diastole).

and $\mathrm{AF}$ in patients with hypertension were significantly lower than in the control subjects (all, $P<.05$ ). On the other hand, the NFV for the patients with hypertension and control subjects was not significantly different $(P=.12)$. Figure 4 plots the AF curves in a cardiac cycle of the 2 groups, demonstrating a global decrease in AF values in the patients with hypertension compared with the control group.

In the hypertension group, univariate linear regression showed that increasing disease duration, PP, and SBP were associated with lower FFV, FPV, RFV, RPV, and AF (all, $P<.05$ ). However, no significant associations between these CSF flow parameters and DBP, age, or sex were found (all, $P>.05$ ) (Table 3). Multiple linear regression analysis showed a negative correlation between SBP and CSF flow dynamics (all, $P<.05$ ) (Table 4 ).

\section{DISCUSSION}

Our study used PCC-MRI to evaluate CSF dynamics in subjects with hypertension. We found that the FFV, FPV, RFV, RPV, and AF of CSF in patients with hypertension were obviously decreased; that disease duration, SBP, and PP significantly negatively correlated with these CSF dynamic parameters; and that SBP was more strongly negatively associated with CSF dynamics compared with disease duration or PP.

The brain is contained within a rigid skull and composed of the brain, CSF, and blood. According to the Monro-Kellie doctrine, any volume change in one intracranial component requires a compensatory change in another. During the systole, there is arterial inflow into the cranium, which initiates a cascade of craniocaudal CSF flush through the cerebral aqueduct (then to the fourth ventricle, subarachnoid space, and arachnoid villi, and finally to the venous sinus) to maintain homeostatic pressure in the cranium, while during the diastole, CSF flows through the aqueduct caudocranially. ${ }^{18-21}$ Therefore, blood circulation is closely related to CSF circulation. Hypertension can lead to atherosclerosis, which reduces the elasticity of cerebral vessels and restricts blood flow to the brain during the systole. ${ }^{15,22-26}$ To the best of our knowledge, however, there has been no study on CSF dynamics in patients with hypertension. In our present study, a significant decrease of FFV and FPV of CSF during the systole; RFV and RPV of CSF during the diastole; and AF throughout the whole cardiac cycle was observed in patients with hypertension, respectively. This finding indicates that the CSF flow dynamics of patients with hypertension is generally in a state of decline. ${ }^{1,2}$

In recent years, a so-called glymphatic system was found in the brain, ie, a paravascular pathway facilitating CSF flow through the brain parenchyma and the clearance of interstitial solutes. ${ }^{1,2}$ In 2018, Mestre et $\mathrm{al}^{4}$ pointed out that arteriosclerosis in hypertensive mice disrupts the above glymphatic flow and sharply slows CSF transportation in the perivascular spaces. This finding might suggest that arteriosclerosis may affect the circulation of CSF and cause changes in the CSF dynamics of the aqueduct in humans. Our study preliminarily investigated the changes of CSF dynamics in patients with hypertension but not the changes of CSF and the insulin sensitivity factor in the perivascular spaces. Therefore, the relationship between them remains unclear and needs further study.

In this study, SBP, PP, and disease duration were negatively correlated with CSF flow dynamics. SBP was more significantly correlated with CSF dynamics than PP. Our results highlight a major limitation of PP, which is "floating" and has no relation to an absolute blood pressure level. For example, a PP of $60 \mathrm{~mm} \mathrm{Hg}$ 
Table 3: Univariate linear regression coefficients for relationships between hypertension parameters and CSF flow parameters ${ }^{\mathrm{a}}$

\begin{tabular}{|c|c|c|c|c|c|}
\hline Variables & $\mathrm{FFV}(\mathrm{mL})^{\mathrm{b}}$ & $\operatorname{FPV}(\mathrm{cm} / \mathrm{s})^{\mathrm{b}}$ & RFV $(m L)^{b}$ & $\operatorname{RPV}(\mathrm{cm} / \mathrm{s})^{\mathrm{b}}$ & $\mathrm{AF}(\mathrm{mL} / \mathrm{min})^{\mathrm{b}}$ \\
\hline Duration & $-0.81(-0.98 \text { to }-0.64)^{c}$ & $-0.83(-0.99 \text { to }-0.67)^{\mathrm{c}}$ & $-0.84(-0.99 \text { to }-0.68)^{c}$ & $-0.83(-0.99 \text { to }-0.67)^{c}$ & $-0.77(-0.95 \text { to }-0.58)^{c}$ \\
\hline PP & $-0.76(-0.95 \text { to }-0.57)^{\mathrm{c}}$ & $-0.73(-1.01 \text { to }-0.71)^{c^{\prime}}$ & $-0.74(-0.94 \text { to }-0.55)^{c}$ & $-0.25(-1.01-0.03)^{c}$ & $-0.74(-0.94 \text { to }-0.54)^{\mathrm{c}}$ \\
\hline SBP & $-0.86(-1.01 \text { to }-0.71)^{c}$ & $-0.86(-0.97 \text { to }-0.62)^{c}$ & $-0.88(-1.02 \text { to }-0.75)^{c}$ & $-0.87(-0.75 \text { to }-0.72)^{c}$ & $-0.83(-0.99 \text { to }-0.67)^{\mathrm{c}}$ \\
\hline DBP & $0.05(-0.33-0.25)$ & $-0.10(-0.39-0.19)$ & $-0.12(-0.41-0.17)$ & $-0.11(-0.40-0.18)$ & $0.04(-0.33-0.25)$ \\
\hline Age & $-0.13(-0.42-0.16)$ & $-0.05(-0.34-0.24)$ & $-0.11(-0.40-0.18)$ & $-0.09(-0.38-0.20)$ & $-0.07(-0.36-0.22)$ \\
\hline Sex & $-0.09(-0.38-0.20)$ & $-0.10(-0.38-0.19)$ & $-0.12(-0.41-0.17)$ & $-0.11(-0.40-0.18)$ & $-0.14(-0.43-0.15)$ \\
\hline
\end{tabular}

${ }^{a}$ Numbers in parentheses are $95 \% \mathrm{Cl}$.

${ }^{\mathrm{b}}$ Crude regression coefficients indicative of increase (positive value) or decrease (negative value) in CSF flow parameters.

${ }^{c} p<.05$.

Table 4: Multiple linear regression coefficients for relationships between hypertension parameters and CSF flow parameters ${ }^{\mathrm{a}}$

\begin{tabular}{|c|c|c|c|c|c|}
\hline Variables & FFV $(m L)^{b}$ & $\operatorname{FPV}(\mathrm{cm} / \mathrm{s})^{\mathrm{b}}$ & RFV (mL) & $\operatorname{RPV}(\mathrm{cm} / \mathrm{s})^{\mathrm{b}}$ & $\mathrm{AF}(\mathrm{mL} / \mathrm{min})^{\mathrm{b}}$ \\
\hline Duration & $-0.34(-0.61 \text { to }-0.07)^{c}$ & $-0.37(-0.64 \text { to }-0.10)^{c}$ & $-0.31(-0.56 \text { to }-0.07)^{c}$ & $-0.35(-0.61 \text { to }-0.09)^{c}$ & $-0.25(-0.55-0.05)^{c}$ \\
\hline SBP & $-0.44(-0.83 \text { to }-0.06)^{c}$ & $-0.50(-0.88 \text { to }-0.12)^{c}$ & $-0.61(-0.97 \text { to }-0.26)^{c}$ & $-0.55(-0.91 \text { to }-0.18)^{c}$ & $-0.50(-0.93 \text { to }-0.08)^{c}$ \\
\hline PP & $-0.25(-0.43-0.13)^{c}$ & $-0.16(-0.33-0.22)^{c}$ & $-0.11(-0.26-0.25)^{c}$ & $-0.23(-0.30-0.24)^{c}$ & $-0.34(-0.45-0.17)^{c}$ \\
\hline
\end{tabular}

${ }^{a}$ Numbers in parentheses are $95 \% \mathrm{Cl}$.

${ }^{\mathrm{b}} \beta$, adjusted regression coefficients indicative of an increase (positive value) or decrease (negative value) in CSF flow parameters.

${ }^{c} p<.05$.

could be associated with a blood pressure of 180/120 $\mathrm{mm} \mathrm{Hg}$ or $120 / 60 \mathrm{~mm} \mathrm{Hg}$. Of note, in addition, SBP is more strongly associated with arteriosclerosis. ${ }^{27}$

In this study, CSF dynamics parameters in the control group were slightly different from those in the previous literature. 6,10,14,20,28-30 This finding may be related to the scan level of the aqueduct and velocity encoding. Anatomically, the cerebral aqueduct is divided into 3 parts, namely, the pars anterior, ampulla, and pars posterior. The pars posterior has the narrowest lumen of the cerebral aqueduct, while the ampulla has the widest lumen. ${ }^{5}$ Because the cerebral aqueduct is very small, partial volume errors can result in falsely lower peak velocities and falsely higher mean flows. Positioning perpendicular to the imaging plane and adjusting the ROI size of the cerebral aqueduct help to minimize this potential source of error. Therefore, in our study, we measured CSF dynamics at the site of ampulla of the aqueduct, the largest part of the lumen. Previous studies measured CSF flow dynamics at a variety of different locations other than the cerebral aqueduct; their results were different from ours. ${ }^{29}$ Also, velocity encoding is an important parameter determining the sensitivity of flow velocity in the examined area. The CSF flow velocity should be the same as or slightly lower than the selected velocity encoding to obtain the optimal signal, ${ }^{31}$ CSF flow velocities greater than velocity encoding can produce aliasing artifacts, whereas velocities much smaller than velocity encoding can result in a weak signal. In a previous study with a 3T Achieva scanner (Philips Healthcare), velocity encoding was set at $10 \mathrm{~cm} / \mathrm{s}^{20}$ In our study, we set velocity encoding to $10 \mathrm{~cm} / \mathrm{s}$ because the maximum velocity was about 7 and $9 \mathrm{~cm} / \mathrm{s}$ in the hypertensive and control groups, respectively.

Our study has several limitations. First, the sample size was relatively small. Therefore, a larger cohort study is needed to validate these results. Second, we did not measure cerebral arterial and venous blood flow. Third, only untreated patients were included in this study. It was reported that cerebral blood flow will recover after blood pressure is controlled in patients with hypertension. ${ }^{23}$ In further studies, we will continue to focus on the changes in CSF flow after treatment in patients with hypertension. Also, patients with $\mathrm{SBP} \geq 180 \mathrm{~mm} \mathrm{Hg}$ were not included in the study because they usually take medicine early due to related symptoms, which did not meet an inclusion criterion of our present study. Last, we did not quantify small white matter lesions on T2WI. ${ }^{32}$ We will study the potential role of these lesions in CSF dynamics in the future.

\section{CONCLUSIONS}

Our study used PCC-MRI to evaluate CSF flow dynamics in treatment-naive patients with essential hypertension. We found that FFV, FPV, RFV, RPV, and AF of CSF in patients with hypertension were significantly decreased. SBP is more strongly negatively associated with these parameters compared with disease duration and PP.

\section{REFERENCES}

1. Jessen NA, Munk AS, Lundgaard I, et al. The glymphatic system: a beginner's guide. Neurochem Res 2015;40:2583-99 CrossRef Medline

2. Iliff JJ, Wang M, Liao Y, et al. A paravascular pathway facilitates CSF flow through the brain parenchyma and the clearance of interstitial solutes, including amyloid. Sci Transl Med 2012;4:147ra111 CrossRef Medline

3. Proulx ST. Cerebrospinal fluid outflow: a review of the historical and contemporary evidence for arachnoid villi, perineural routes, and dural lymphatics. Cell Mol Life Sci 2021;78:2429-57 CrossRef Medline

4. Mestre H, Tithof J, Du T, et al. Flow of cerebrospinal fluid is driven by arterial pulsations and is reduced in hypertension. Nat Commun 2018;9:4878 CrossRef Medline

5. Edelman RR, Wedeen VJ, Davis KR, et al. Multiphasic MR imaging: a new method for direct imaging of pulsatile CSF flow. Radiology 1986;161:779-83 CrossRef Medline

6. Akay R, Kamisli O, Kahraman A, et al. Evaluation of aqueductal CSF flow dynamics with phase contrast cine MR imaging in idiopathic intracranial hypertension patients: preliminary results. Eur Rev Med Pharmacol Sci 2015;19:3475-79 Medline

7. Battal B, Kocaoglu M, Bulakbasi N, et al. Cerebrospinal fluid flow imaging by using phase-contrast MR technique. $\mathrm{Br} J$ Radiol 2011;84:758-65 CrossRef Medline 
8. Kelly EJ, Yamada S. Cerebrospinal fluid flow studies and recent advancements. Semin Ultrasound CT MR 2016;37:92-99 CrossRef Medline

9. Lee JH, Lee HK, Kim JK, et al. CSF flow quantification of the cerebral aqueduct in normal volunteers using phase contrast cine MR imaging. Korean J Radiol 2004;5:81-86 CrossRef Medline

10. Hasiloglu ZI, Albayram S, Gorucu Y, et al. Assessment of CSF flow dynamics using PC-MRI in spontaneous intracranial hypotension. Headache 2012;52:808-19 CrossRef Medline

11. Qvarlander S, Ambarki K, Wåhlin A, et al. Cerebrospinal fluid and blood flow patterns in idiopathic normal pressure hydrocephalus. Acta Neurol Scand 2017;135:576-84 CrossRef Medline

12. Hoxworth JM. Measuring CSF flow dynamics in spontaneous intracranial hypotension with phase-contrast magnetic resonance imaging: potential implications for diagnosis and treatment. Cephalalgia 2014;34:565-67 CrossRef Medline

13. Lindstrøm EK, Ringstad G, Mardal K, et al. Cerebrospinal fluid volumetric net flow rate and direction in idiopathic normal pressure hydrocephalus. Neuroimage Clin 2018;20:731-41 CrossRef Medline

14. Yilmaz TF, Aralasmak A, Toprak H, et al. Evaluation of CSF flow metrics in patients with communicating hydrocephalus and idiopathic intracranial hypertension. Radiol Med 2019;124:382-91 CrossRef Medline

15. Feihl F, Liaudet L, Waeber B. The macrocirculation and microcirculation of hypertension. Curr Hypertens Rep 2009;11:182-89 CrossRef Medline

16. Muntner P, Carey RM, Gidding S, et al. Potential U.S. population impact of the $2017 \mathrm{ACC} / \mathrm{AHA}$ high blood pressure guideline. $\mathrm{J} \mathrm{Am}$ Coll Cardiol 2018;71:109-18 CrossRef Medline

17. Gardner MJ, Altman DG. Confidence intervals rather than P values: estimation rather than hypothesis testing. BMJ (Clin Res Ed) 1986;292:746-50 CrossRef Medline

18. Sakhare AR, Barisano G, Pa J. Assessing test-retest reliability of phase contrast MRI for measuring cerebrospinal fluid and cerebral blood flow dynamics. Magn Reson Med 2019;82:658-70 CrossRef Medline

19. Kim D, Czosnyka Z, Kasprowicz M, et al. Continuous monitoring of the Monro-Kellie doctrine: is it possible? J Neurotraum 2012;29:135463 CrossRef Medline

20. ElSankari S, Balédent O, van Pesch V, et al. Concomitant analysis of arterial, venous, and CSF flows using phase-contrast MRI: a quantitative comparison between MS patients and healthy controls. $J$ Cereb Blood Flow Metab 2013;33:1314-21 CrossRef Medline
21. Bhadelia RA, Bogdan AR, Kaplan RF, et al. Cerebrospinal fluid pulsation amplitude and its quantitative relationship to cerebral blood flow pulsations: a phase-contrast MR flow imaging study. Neuroradiology 1997;39:258-64 CrossRef Medline

22. Pires PW, Dams Ramos CM, Matin N, et al. The effects of hypertension on the cerebral circulation. Am J Physiol Heart Circ Physiol 2013;304:H1598-614 CrossRef Medline

23. Meyer JS, Rogers RL, Mortel KF. Prospective analysis of long term control of mild hypertension on cerebral blood flow. Stroke 1985;16:985-90 CrossRef Medline

24. Li Y, Shen Q, Huang S, et al. Cerebral angiography, blood flow and vascular reactivity in progressive hypertension. Neuroimage 2015;111:329-37 CrossRef Medline

25. Domanski M, Norman J, Wolz M, et al. Cardiovascular risk assessment using pulse pressure in the first national health and nutrition examination survey (NHANES I). Hypertension 2001;38:793-97 CrossRef Medline

26. Safar ME. Pulse pressure, arterial stiffness, and cardiovascular risk Curr Opin Cardiol 2000;15:258-63 CrossRef Medline

27. Mosley WJ, Greenland P, Garside DB, et al. Predictive utility of pulse pressure and other blood pressure measures for cardiovascular outcomes. Hypertension 2007;49:1256-64 CrossRef Medline

28. Stoquart-ElSankari S, Balédent O, Gondry-Jouet C, et al. Aging effects on cerebral blood and cerebrospinal fluid flows. J Cereb Blood Flow Metab 2007;27:1563-72 CrossRef Medline

29. Luetmer PH, Huston J, Friedman JA, et al. Measurement of cerebrospinal fluid flow at the cerebral aqueduct by use of phase-contrast magnetic resonance imaging: technique validation and utility in diagnosing idiopathic normal pressure hydrocephalus. Neurosurgery 2002;50:534-43 CrossRef Medline

30. Oner Z, Kahraman AS, Kose E, et al. Quantitative evaluation of normal aqueductal cerebrospinal fluid flow using phase-contrast cine MRI according to age and sex. Anat Rec (Hoboken) 2017;300:549-55 CrossRef Medline

31. Bapuraj JR, Londy FJ, Delavari N, et al. Cerebrospinal fluid velocity amplitudes within the cerebral aqueduct in healthy children and patients with Chiari I malformation. J Magn Reson Imaging 2016;44:463-70 CrossRef Medline

32. Yu X, Wang G, Zhan J, et al. Risk factors of pure leukoaraiosis and the association with preclinical carotid atherosclerosis. Atherosclerosis 2018;275:328-32 CrossRef Medline 